UK)

Copper-Catalyzed Carboarylation of Alkynes via Vinyl Cations

J. Am. Chem. Soc. 2013, 135, 12532-12535.

\title{
Synthesis of Nafoxidine via Copper-Catalyzed Carboarylation
}

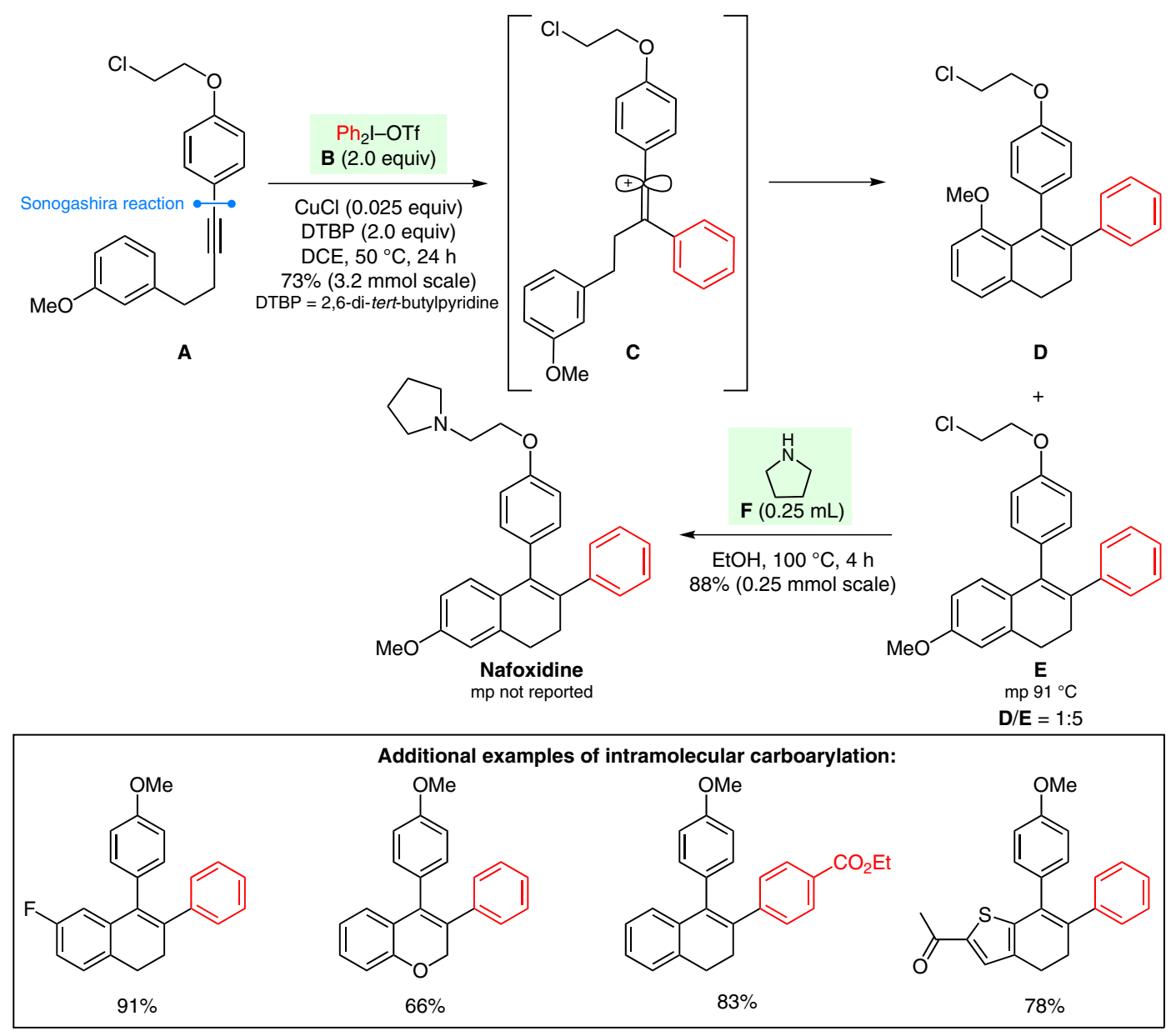

Significance: Nafoxidine is a nonsteroidal antiestrogenic agent. The synthesis depicted features a copper-catalyzed alkyne carboarylation initiated through activation of diphenyliodonium triflate $(\mathbf{B})$. The resultant catalytically generated aromatic electrophile equivalent reacts with the electronrich alkyne $\mathbf{A}$ to form a stabilized trisubstituted vinyl cation type intermediate $\mathbf{C}$ that then undergoes a regioselective intramolecular Friedel-Crafts reaction to afford the dihydronaphthalene $\mathbf{E}$ preferentially.

SYNFACTS Contributors: Philip Kocienski

Synfacts 2013, 9(12), 1255 Published online: 18.11.2013

Dol: 10.1055/s-0033-1340063; Reg-No.: K06713SF

\section{Category}

Synthesis of Natural

Products and

Potential Drugs

\section{Key words}

nafoxidine

copper-catalyzed carboarylation

diaryliodonium triflates

alkynes

vinyl cations
Comment: The scope of the carboarylation was explored via 31 examples, 28 of which were successful. The electronic requirements for the substituent on the alkyne were more rigid: It is essential to have a group capable of stabilizing the vinyl cation. Unsymmetrical analogues of the iodonium triflate $\mathbf{B}$ bearing a substituted arene and a mesityl group transferred the arene selectively. One example of an intermolecular carboarylation is described. 